\title{
Acute Respiratory Toxicity in Patients with Exposure to Common Household Chemical Products: A Retrospective Study on Patients Admitted to the ICU of Poison Control Center - Ain Shams University from April 2011 to April 2012
}

\author{
Manal El- Sayed Abd El-Salam, Hoda Mohamed Salah Eldin, and Noha \\ Mohammed Ahmed Awadi
}

\footnotetext{
${ }^{1}$ Forensic Medicine and Clinical Toxicology Department, Faculty of Medicine, Ain Shams University, Cairo, Egypt.
}

\begin{abstract}
Background: Poisoning with household chemical products can be attributed to their availability and easy accessibility. Poisoning by many common household products may be associated with the development of various respiratory symptoms. Accordingly, this work was conducted to study and evaluate the pattern and outcome of acute respiratory toxicity caused by common household chemical products exposure in patients who were admitted to the intensive care unit (ICU) of the Poison Control Center (PCC) Ain Shams University Hospitals.

Method: A hospital-based retrospective study on 149 patients with acute respiratory toxicity related to common household intoxication admitted to ICU of the PCC Ain Shams University Hospitals from April 2011 to April 2012. Data regarding age, sex, data of intoxication, type of toxic agents, clinical and investigational data on admission, management and outcome were recorded and analyzed

Results: Pediatric age represented $55.7 \%$ of cases and number of females slightly exceeded that of males. Poisoning was predominantly accidental. Toxic agents included cholinesterase inhibitors, hydrocarbons, corrosives, and carbon monoxide. Respiratory distress was the predominant cause for ICU admission. Complete cure was the fate of $75.2 \%$ of the cases, while mortality occurred in $16.8 \%$ of cases

Conclusions: Household poisoning is still responsible for a considerable number of poisoning and deaths. Preventive strategies adopted at a national level are the key measures to reduce the incidence of poisoning with household chemicals.
\end{abstract}

\section{Introduction}

$\mathrm{H}$ ousehold chemicals make a heterogeneous group of products in use, chemical composition, and toxic potential. What is common for these products is that they are easily accessible to children and adults in their homes, gardens, or garages, and are often involved in suspected poisoning incidents reported to the poison control centers all over the world (Klepacet al., 2000).

Substances most commonly involved in household poisoning incidents are insecticides, organic solvents, corrosives, and carbon monoxide; all are known tocause respiratory compromise (Smith, 1999; Holland, 2007 and Palmer and Phillips, 2007).

Acute respiratory failure (ARF) and respiratory insufficiency are the most common causes of intensive care unit (ICU) admissions.Unlike many patients with diseases managed in the ICU, poisoned patients often do not have a well-recognized clinical course or predictable complications(Kirk and Pope, 2006 and Ghoneimet al., 2013).

The aim of this work is to study and evaluate the age and sex distribution, incidence, pattern and outcome of acute respiratory toxicity caused by common household chemical products exposure

\section{Methodology}

The present study was planned as hospital-based cross sectional retrospective study. The study protocol was reviewed and approved by both the ethical committeeof Ain Shams Faculty of Medicine and the head of PCC. It was carried out on all patients with acute respiratory toxicity related to common household intoxication admitted to the intensive care unit (ICU) of the Poison Control Center (PCC) of Ain Shams 
University Hospitals. The study is covering a period of one year starting from April 2011 to April 2012. No patients were excluded from the study.

Data were collected from the preformatted sheets used by medical staff to collect data on all poisoning cases. Confidentiality of reports was maintained by keeping the records anonymous. Data werefed into a data collection sheet and then statistically analyzed, including the following parameters: demographic data, data of intoxication, type of toxic agent, clinical and investigational data on admission, management, and outcome.

\section{Results}

During the study period, a total of 21550 casesintoxicated patients were presented to the PCC.15.5\% of cases(3342) were due tohousehold chemicals of which 149 patients of both sexes were admitted to the ICU (El Masry and Tawfik, 2011).

\section{Demographic data}

Ages for both sexes ranged from 10 months to 60 years. Chart (1) shows that child age represented (83) $55.7 \%$ of cases while adult cases represented (66) $44.3 \%$.Regarding child age cases, toddlers $(0-2$ years $)$ and preschool age(3-5years) represented the majority of cases( $46 \%$ and $37 \%$ respectively), while school age represented $17 \%$. Sex distribution of cases was (78) $52.3 \%$ females and (71) $47.7 \%$ males.More females were involved in both child and adult cases $(53.0 \%$ and $51.5 \%$ respectively).

\section{Data of intoxication}

Most cases were related to accidental exposure (72\%), while suicidal attempts represented $28 \%$ of cases. Table (1) shows that exposure was accidental for most child age cases $(97.6 \%)$ and among $40.9 \%$ of adult cases.

Ingestion was the main route of exposure $(85.2 \%)$, followed by dermal exposure $(8.7 \%)$, and inhalation $(6 \%)$.

The mean delay time among all cases was $10.62 \pm 34.48$ hours, with minimum of 30 minutes and maximum of two days. The highest delay time was related to corrosive cases $(30.4 \pm 78.1 \mathrm{~h})$, while the lowest was related to cholinesterase inhibitors $(4.8 \pm 4.3$ h).

\section{Type of toxic agents}

Chart (2) shows that $36.9 \%$ of cases were exposed to cholinesterase inhibitors followed by hydrocarbons $(20.8 \%)$, corrosives $(17.4 \%)$ then carbon monoxide (13.4\%) while exposure to cholinesterase inhibitors combined to hydrocarbons represented $11.4 \%$ of cases.

As regards cases exposed to cholinesterase inhibitors in this study, $50.9 \%$ of cases were due to malathion exposure. Carbamate exposure accounted for $43.6 \%$, while $5.5 \%$ of cases were exposed to unknown agents. Kerosene exposure represented the majority of hydrocarbon cases $(93.5 \%)$, while thinner exposure represented only $6.5 \%$.As regards corrosive cases, half of cases were due to potash exposure $(50 \%)$ and the rest were due to exposure to chlorine (26.9\%), sulphuric acid $(15.4 \%)$, or miscellaneous detergents $(7.7 \%)$.

\section{Clinical and investigational data on admission}

Respiratory distress represented the most common cause of ICU admission among all cases (34.3\%), followed by pulmonary edema $(31.5 \%)$, respiratory failure $(27.5 \%)$, while $(6.7 \%)$ only were due to pneumonia.

A statistically significant difference was observed between different toxic agents as regards causes of admission to the ICU. Pulmonary edema was the main presentation among cases exposed to cholinesterase inhibitors (60.0\%).74.2\% of hydrocarbon cases were linked to respiratory distress, while none were due to pulmonary edema. Cases of combined cholinesterase inhibitors and hydrocarbon exposure were presented by respiratory distress $(52.9 \%)$ and pulmonary edema (29.4\%), while no cases presented by pneumonia. Corrosive cases were presented by respiratory distress $(53.8 \%)$ and pneumonia $(23.1 \%)$ while pulmonary edema and respiratory failure each were only presented by $11.5 \%$ of cases. Respiratory failure was the commonest cause of ICU admission (55\%) among carbon monoxide intoxication cases, while no cases were presented by pneumonia.

Duration of ICU stay ranged from a minimum of 4 hours to a maximum of one month. Table (3) shows that there was statistically significant difference between different toxic agents as regards duration of ICU stay (days) where carbon monoxide cases represented the highest mean duration of admission (5.8 \pm 4.6 day). This was followed by cases with cholinesterase inhibitors, corrosive cases, combined cholinesterase inhibitors and hydrocarbon exposure. Hydrocarbon cases represented the lowest mean duration of admission (1.7 \pm 1.4 day).

Regarding acid-base disturbances, 54.4\% showed respiratory acidosis, followed by mixed respiratory and metabolic acidosis (30.2\%) and metabolic acidosis $(8.7 \%)$, while both respiratory alkalosis and normal $\mathrm{ABG}$ were represented by $3.4 \%$ of cases.

There was a statistically significant difference between toxic agents as regards the occurrence of respiratory acidosis (Table 4). Respiratory acidosis was the main presentation in cholinesterase inhibitors cases, hydrocarbon cases, carbon monoxide cases and combined cholinesterase inhibitors and hydrocarbon exposure $(65.5 \%, \quad 61.3 \%, \quad 60.0 \%$ and $58.8 \%$ respectively), while represented only $15.4 \%$ of cases of corrosive cases. On the other hand, there was no significant difference between different toxic as regards other $A B G$ findings; including normal $A B G$, metabolic acidosis, respiratory alkalosis and mixed respiratory and metabolic acidosis.

\section{Management data}

Forty-three percent of cases (64) were in need to mechanical ventilation. Table (5) shows that there was a statistically significant difference between different toxic cases as regards the need for mechanical 
ventilation (MV). Table (5) also shows that $70 \%$ of $\mathrm{CO}$ intoxicated cases needed MV, followed by $67.3 \%$ of cholinesterase inhibitors cases, $41.2 \%$ of combined ChEIs and hydrocarbon cases, and $19.2 \%$ of corrosive cases while only $3.2 \%$ of hydrocarbon cases needed MV.

\section{Outcome}

Complete cure was the fate of $75.2 \%$ (112) of cases, while $16.8 \%$ (25) of cases died and $8.1 \%$ (12) of cases showed morbidity (Chart 3 ).

Table (6) shows that there was a statistically significant difference among different toxic agents as regards mortality. $40 \%$ of mortality occurred among carbon monoxide cases compared to while none of combined cholinesterase inhibitors and hydrocarbon exposed cases died.

Table (1): Chi square statistical analysis of 149 cases with acute respiratory toxicity due to household products admitted to the ICU of the PCCfrom April 2011-April 2012according to age and mode of poisoning

\begin{tabular}{|c|c|c|c|c|c|c|c|}
\hline & \multicolumn{4}{|c|}{ Cases } & \multirow{3}{*}{$\mathbf{X}^{2}$} & \multirow{3}{*}{$\mathbf{P}$} \\
\hline & & \multicolumn{2}{|c|}{ Child } & \multicolumn{2}{|c|}{ Adult } & & \\
\hline & & $\mathbf{N}$ & $\%$ & $\mathbf{N}$ & $\%$ & & \\
\hline \multirow[t]{2}{*}{ Manner of poisoning } & Accidental & 81 & $97.6 \%$ & 27 & $40.9 \%$ & \multirow[t]{2}{*}{59.2} & \multirow[t]{2}{*}{$.0001 *$} \\
\hline & Suicidal & 2 & $2.4 \%$ & 39 & $59.1 \%$ & & \\
\hline
\end{tabular}

$N=$ number of cases; $P=$ probability; $p<0.01=$ significant difference $=*$

Table (2): Chi square and Fisher's exact statistical analysis of 149 cases with acute respiratory toxicity due to household products admitted to the ICU of the PCCfrom April 2011-April 2012 according tocauses of the ICU admissionand different toxic agents

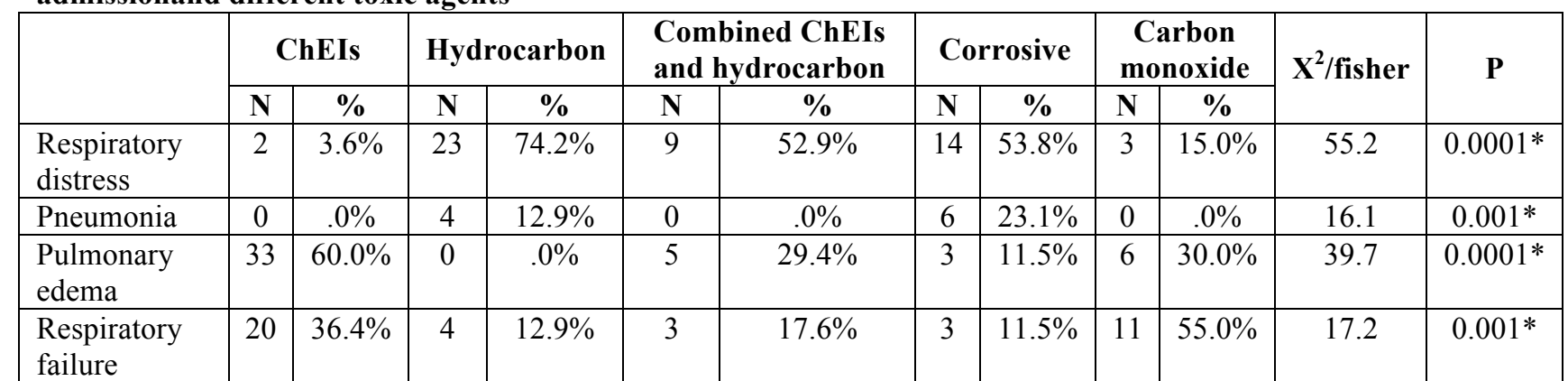

$N=$ number of cases; $P=$ probability; $p<0.01=$ significant difference $=* ;$ ChEIs $=$ Cholinesterase inhibitors

Table (3): Kruskal-Wallis statistical analysis of 149 cases with acute respiratory toxicity due to household products admitted to the ICU of the PCCfrom April 2011-April 2012 according to duration of ICU stayand type of toxic agent

\begin{tabular}{|c|c|c|c|}
\hline Toxic agents & $\begin{array}{c}\text { Duration of ICU stay (day) } \\
\text { Mean } \pm \text { SD }\end{array}$ & Test value & $\mathbf{P}$ \\
\hline ChEIs & $4.9 \pm 6.4$ & \multirow[t]{5}{*}{24.72} & \multirow[t]{5}{*}{$0.0001 *$} \\
\hline Hydrocarbon & $1.7 \pm 1.4$ & & \\
\hline Combined ChEIs and hydrocarbon & $2.3 \pm 2.1$ & & \\
\hline Corrosive & $4.6 \pm 4.3$ & & \\
\hline Carbon monoxide & $5.8 \pm 4.6$ & & \\
\hline
\end{tabular}

$N=$ number of cases; $P=$ probability; $p<0.01=$ significant difference $=* ;$ ChEIs $=$ Cholinesterase inhibitors

Table (4): Chi-square and Fisher's exact statistical analysis of 149 cases with acute respiratory toxicity due to household products admitted to the ICU of the PCCfrom April 2011-April 2012 according to acid-base disturbance in $\mathrm{ABG}$ pictures and type of toxic agent

\begin{tabular}{|c|c|c|c|c|c|c|c|c|c|c|c|c|}
\hline \multirow{2}{*}{$\begin{array}{c}\text { Acid- } \\
\text { base } \\
\text { disturbance }\end{array}$} & \multicolumn{2}{|c|}{ ChEIs } & \multicolumn{2}{|c|}{ Hydrocarbon } & \multicolumn{2}{|c|}{$\begin{array}{l}\text { Combined ChEIs } \\
\text { and hydrocarbon }\end{array}$} & \multicolumn{2}{|c|}{ Corrosive } & \multicolumn{2}{|c|}{$\begin{array}{c}\text { Carbon } \\
\text { Monoxide }\end{array}$} & \multirow{2}{*}{$\begin{array}{c}\mathbf{X}^{2} \\
\text { /fisher }\end{array}$} & \multirow[t]{2}{*}{$\mathbf{P}$} \\
\hline & $\mathbf{N}$ & $\%$ & $\mathbf{N}$ & $\%$ & $\mathbf{N}$ & $\%$ & $\mathbf{N}$ & $\%$ & $\mathbf{N}$ & $\%$ & & \\
\hline $\begin{array}{l}\text { Respiratory } \\
\text { Acidosis }\end{array}$ & 36 & $65.5 \%$ & 19 & $61.3 \%$ & 10 & $58.8 \%$ & 4 & $15.4 \%$ & 12 & $60.0 \%$ & 19.6 & $.001 *$ \\
\hline Normal & 11 & $20.0 \%$ & 8 & $25.8 \%$ & 4 & $23.5 \%$ & 7 & $26.9 \%$ & 4 & $20.0 \%$ & 0.917 & 0.942 \\
\hline $\begin{array}{l}\text { Metabolic } \\
\text { Acidosis }\end{array}$ & 4 & $7.3 \%$ & 5 & $16.1 \%$ & 1 & $5.9 \%$ & 3 & $11.5 \%$ & 0 & $.0 \%$ & 4.2 & 0.358 \\
\hline $\begin{array}{l}\text { Respiratory } \\
\text { alkalosis }\end{array}$ & 0 & $.0 \%$ & 1 & $3.2 \%$ & 0 & $.0 \%$ & 2 & $7.7 \%$ & 2 & $10.0 \%$ & 6.2 & 0.075 \\
\hline $\begin{array}{l}\text { Resp and met. } \\
\text { acidosis }\end{array}$ & 14 & $25.5 \%$ & 5 & $16.1 \%$ & 6 & $35.3 \%$ & 14 & $53.8 \%$ & 6 & $30.0 \%$ & 10.6 & 0.031 \\
\hline
\end{tabular}

$N=$ number of cases; $P=$ probability; $p<0.01=$ significant difference $=* ;$ ChEIs $=$ Cholinesterase inhibitors 
Table (5): Chi-square statistical analysis of 149 cases with acute respiratory toxicity due to household products admitted to the ICU of the PCCfrom April 2011-April 2012 according to need of mechanical ventilation and type of toxic agent

\begin{tabular}{|c|c|c|c|c|c|c|c|c|c|c|c|c|}
\hline \multirow{2}{*}{$\begin{array}{c}\text { Mechanical } \\
\text { ventilation }\end{array}$} & \multicolumn{2}{|c|}{ ChEIs } & \multicolumn{2}{|c|}{ Hydrocarbon } & \multicolumn{2}{|c|}{$\begin{array}{l}\text { Combined ChEIs } \\
\text { and hydrocarbon }\end{array}$} & \multicolumn{2}{|c|}{ Corrosive } & \multicolumn{2}{|c|}{$\begin{array}{c}\text { Carbon } \\
\text { monoxide }\end{array}$} & \multirow[t]{2}{*}{$\mathbf{X}^{2}$} & \multirow[t]{2}{*}{$\mathbf{P}$} \\
\hline & $\mathbf{N}$ & $\%$ & $\mathbf{N}$ & $\%$ & $\mathbf{N}$ & $\%$ & $\mathbf{N}$ & $\%$ & $\mathbf{N}$ & $\%$ & & \\
\hline Yes & 37 & $67.3 \%$ & 1 & $3.2 \%$ & 7 & $41.2 \%$ & 5 & $19.2 \%$ & 14 & $70.0 \%$ & \multirow{2}{*}{45.2} & \multirow{2}{*}{$.0001^{*}$} \\
\hline No & 18 & $32.7 \%$ & 30 & $96.8 \%$ & 10 & $58.8 \%$ & 21 & $80.8 \%$ & 6 & $30.0 \%$ & & \\
\hline
\end{tabular}

$N=$ number of cases; $P=$ probability; $p<0.01=$ significant difference $=* ;$ ChEIs $=$ Cholinesterase inhibitors

Table (6): Fisher's Exact statistical analysis of 149 cases with acute respiratory toxicity due to household products admitted to the ICU of the PCC from April 2011-April 2012 according to type of toxic agent and outcome

\begin{tabular}{|c|c|c|c|c|c|c|c|c|c|c|c|c|c|}
\hline & \multicolumn{2}{|c|}{ ChEIs } & \multicolumn{2}{|c|}{ Corrosive } & \multicolumn{2}{|c|}{ Hydrocarbon } & \multicolumn{2}{|c|}{$\begin{array}{c}\text { Carbon } \\
\text { monoxide }\end{array}$} & \multicolumn{2}{|c|}{$\begin{array}{c}\text { ChEIs + } \\
\text { hydrocarbon }\end{array}$} & \multirow{2}{*}{$\begin{array}{c}\text { Fisher's } \\
\text { Exact }\end{array}$} & \multirow[t]{2}{*}{$\mathbf{P}$} \\
\hline & & $\mathbf{N}$ & $\%$ & $\mathbf{N}$ & $\%$ & $\mathbf{N}$ & $\%$ & $\mathbf{N}$ & $\%$ & $\mathbf{N}$ & $\%$ & & \\
\hline \multirow[t]{2}{*}{ Mortality } & Yes & 12 & 21.8 & 3 & 11.5 & 2 & 6.5 & 8 & 40 & 0 & 0 & \multirow[t]{2}{*}{13.8} & \multirow[t]{2}{*}{$0.005^{*}$} \\
\hline & No & 43 & 78.2 & 23 & 88.5 & 29 & 93.5 & 12 & 60 & 17 & 100 & & \\
\hline \multirow[t]{2}{*}{ Morbidity } & Yes & 5 & 9.1 & 1 & 3.8 & 0 & .0 & 5 & 25 & 1 & 5.9 & \multirow[t]{2}{*}{9.21} & \multirow[t]{2}{*}{$00.028 *$} \\
\hline & No & 50 & 90.9 & 25 & 96.2 & 31 & 100 & 15 & 75 & 16 & 94.1 & & \\
\hline \multirow[t]{2}{*}{ Cure } & Yes & 38 & 69.1 & 22 & 84.6 & 29 & 93.5 & 7 & 35 & 16 & 94.1 & \multirow[t]{2}{*}{26.89} & \multirow[t]{2}{*}{$.0001 *$} \\
\hline & No & 17 & 30.9 & 4 & 15.4 & 2 & 6.5 & 13 & 65 & 1 & 5.9 & & \\
\hline
\end{tabular}

$N=$ number of cases; $P=$ probability; $p<0.01=$ significant difference $=*$; ChEIs $=$ Cholinesterase inhibitors
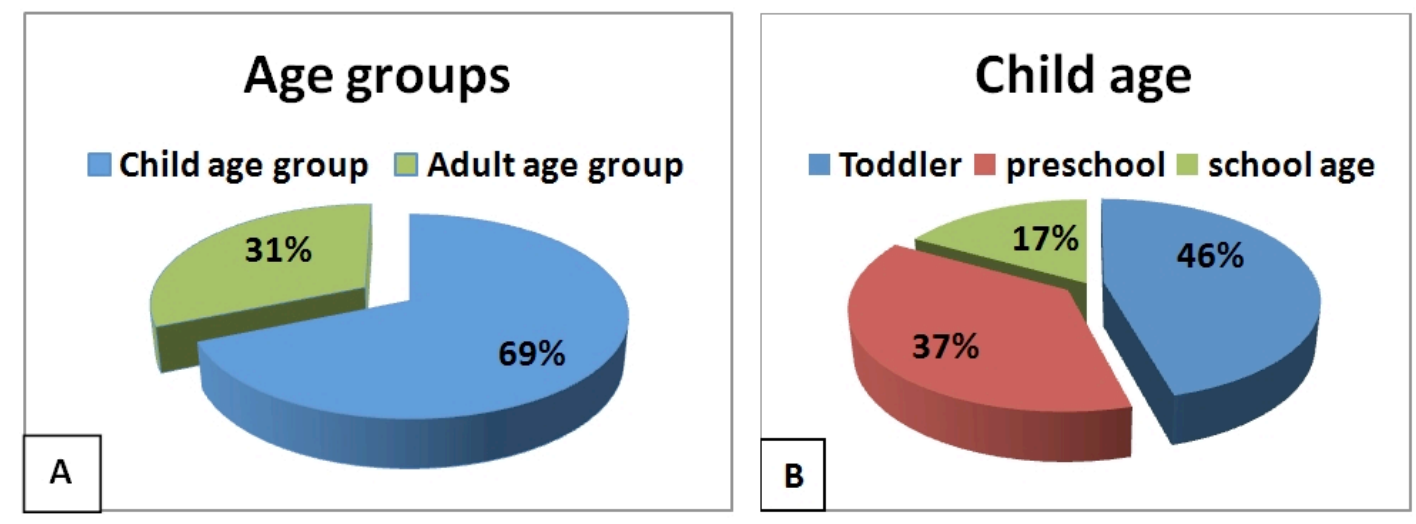

Chart (1): distribution of age groups among 149 cases with acute respiratory toxicity due to household products admitted to the ICU of the PCC from April 2011-April 2012. A) Child and adult age among all cases; B) Toddlers, preschool age, and school age among child age cases.

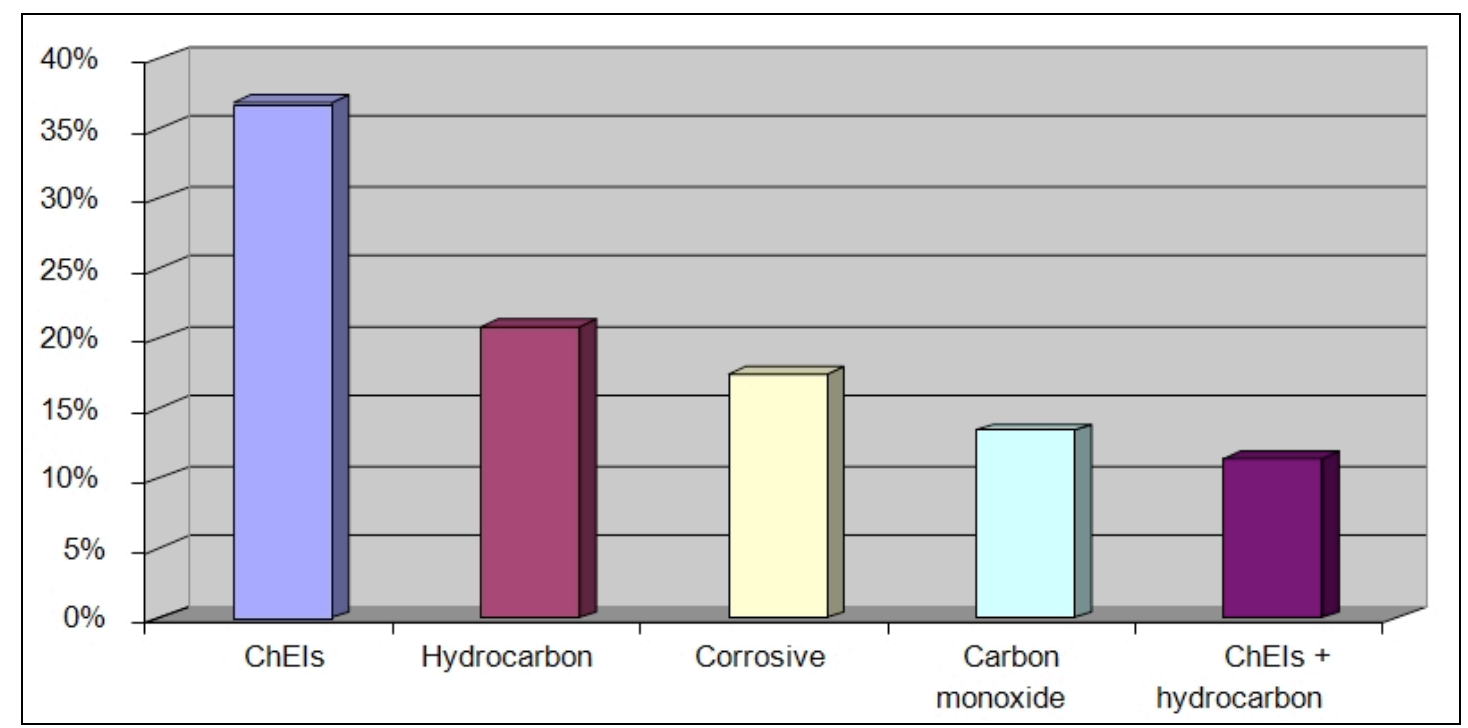

Chart (2): showing distribution of different toxic agents among 149 cases with acute respiratory toxicity due to household products admitted to the ICU of the PCC from April 2011-April 2012 (ChEIs= Cholinesterase inhibitors). 


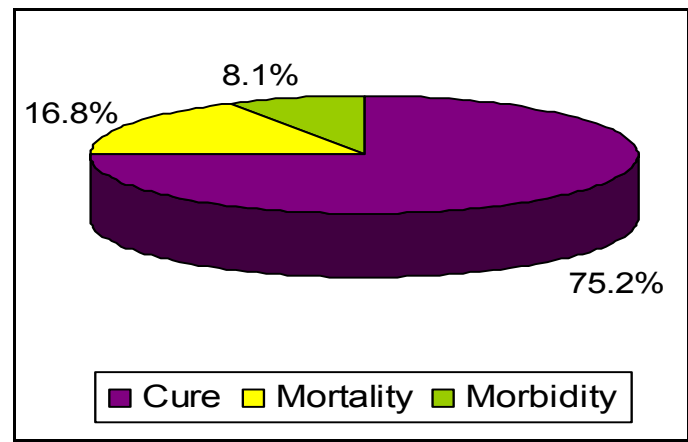

Chart (3): Description of the different outcomes among 149 cases with acute respiratory toxicity due to household products admitted to the ICU of the PCC Hospitals from April 2011-April 2012.

\section{Discussion}

Poisoning due to household chemical products is considered a serious problem nowadays. Respiratory compromise isone of the most common factors contributing to death from poisoning resulting from airway obstruction, loss of airway-protective reflexes, direct pulmonary damage, pulmonary edema, toxininduced metabolic acidosis and respiratory depression (Meyer et al., 2007).

Despite the increasing incidents of household products poisoning all over the world and the resultant serious injury and death due to exposures to these products annually, little work has been published in the area of household chemical poisoning (Balme et al., 2012 and Cantrell et al., 2013).

This clinical study aimed at describing the pattern of common household products poisoning that led to admission to the intensive care unit (ICU) due to acute respiratory problems. This was achieved by analysis of retrospectively collected data of 149 patients admitted to ICU of the Poison Control Center (PCC) of Ain Shams University Hospitals in the period from April 2011 to April 2012.

This study showed that the pediatric age group was more susceptible to exposure to household chemicalscompared to adults.Accidental poisoning outnumbered suicidal attempts (represented $27.5 \%$ of cases) and was recorded among most of children cases (97.6\%) compared to adult cases (40.9\%).

Previous studies from Pakistan and USA by Manzar et al., (2010) and Bronstein et al. (2011) respectively also showed a high prevalence of unintentional intoxication with non- pharmaceutical products in children. This is secondary to the explorative behavior of children, their tendency to place objects in the mouth and access to unsecured substances (Meyer et al, 2007).

A female predominance among both pediatric and adult cases was noted; a finding similarly recorded in Brazil by Fook et al. (2013). This can be attributed to the fact that females are the major users of household cleaning products and indoor pesticides and consequently may be exposed to these products accidentally, due to inappropriate storage, food contamination, or incorrect product use (Habib et al., 2006 and Presgrave et al., 2008).
The relative frequency of suicide with the household products ( $28 \%$ of cases) may be related to the impulsive behavior of suicidal patients who chose their poison on the basis of availability either in or near to their home (Eddleston et al., 2006).

Route of exposure was mainly oral ingestion $(85.2 \%)$, followed by dermal exposure $(8.7 \%)$, while inhalation represented only $(6 \%)$ of cases. This agreed with Al-Shehri, (2004) who related this to the fact that common household chemicals are usually in liquid forms.

The mean delay time among all cases in the current study was relatively long (10.62 h.), which may be a contributing factor for clinical severity; an association reported by Chowell et al., (2006).

The highestmean delay time was observed among cases of corrosivecases.Similar delayed presentation among corrosive cases was observed by Ekpe and Ette (2012). This can be explained by the fact thatdevastating complications can occureven with lowgrade probably underestimated corrosive injuries (Lupa et al, 2009). This is in comparison to the lowest mean delay time noted in cholinesterase inhibitors caseswhere respiratory symptoms usually require immediate intervention (Eddleston, 2008).

Cholinesterase inhibitors cases represented $36.9 \%$ of cases and were mainly due to malathionand carbamate.These results may be explained by the ready availability of agricultural pesticides which became a common household product in many rural areas of the developing world in the last decades (Meyer et al., 2007).

Additionally, the relatively higher incidence of malathion poisoning compared to carbamate in the current study can be attributed to the inability of carbamates to penetrate the CNS (with subsequent less central respiratory depression), as well as the spontaneousreactivating of acetylcholinestraseenzyme making the duration of symptoms and severity of carbamate poisoning generally less than malathion (Tracqui et al., 2001).

Hydrocarbons were the second common toxic agents $(20.8 \%)$ of which kerosene exposure represented the majority, while thinner exposure represented only $6.5 \%$ of cases. The higher incidence 
of kerosene poisoning in the present study is similarly observed in India and Malaysia by Singh et al. (2012) and Sulastri et al. (2012) who attributed this to its extensive usage as a fuel and light source in the developing world in contrast to thinner which usually has limited household use as a solvent and paintremover.Kerosene is also more related to respiratory problems as it belongs to the aliphatic group of hydrocarbons which are easily aspirated following ingestion (Singh et al., 2009).

Corrosives cases represented (17.4\%) of cases. Potash was the most common caustic substance followed by acids (chlorine and sulphuric acid). Similar findings were reported by Arici et al. (2012). Similarly, Johnson and Brigger (2012) reported that ingestion of alkali was more prevalent than that of acid Injury. In the present study, which focuses on the severe cases, the higher incidence of potash cases may be explained by the fact that even lower concentrations of alkali can produce extensive injury, tend to injure the upper airway and cause laryngeal edema and airway compromise (Lupa et al, 2009).

The low prevalence of carbon monoxide poisoning cases $(13.4 \%)$ in the present study is explained by the fact that the earliest and severestmanifestations of carbon monoxide poisoning are more pronounced in oxygen-dependent organs (the brain and the heart) while respiratory symptoms (the main concern of our study) are more common in patients having a previous respiratory compromise (Kao and Nanagas, 2004 and Sideras, 2008).

Combined ChEIs and hydrocarbons poisoning in the present study, is represented by low percentage of cases (11.4\%) and this can be explained according to Fishel and Andre (2002) and Sadaka et al., (2011) who noted that such exposure usually occurs through skin during treatment of lice and dermal exposure has relatively low incidence of severe poisoning compared to systemic poisoning.

Respiratory distress was the most common cause of ICU admission among all cases.

This can be explained according to Deorari (2005) who stated that respiratory distress is the primary manifestation for many pulmonary conditions including acute respiratory distress syndrome (ARDS), pneumonia, aspiration, asphyxia and acidosis. A low incidence of pneumonia as a cause of ICU admissionwas also noted. This may be attributed to the fact that the indication of ICU admission in pneumonia is limited to the development of respiratory failure requiring intubation and mechanical ventilation (Marrie and Shariatzadeh, 2007).

In the present study, it was observed that there was statistically significant difference between different toxic agents as regards causes of admission to the ICU.Pulmonary edema was the main presentation among ChEIs cases. This can be attributed to the increase in pulmonary capillary permeability (highpermeability edema) due to hypoxia, respiratory failure, and parasympathetic discharge that is related to the anticholinesterase activity of the toxicant (Hoffman, 2006).

A predominance of respiratory distress as the primary causes of ICU admission in hydrocarbon cases was noted in the current study and similarly observed by Abdel Raouf (2012). This can be explained by the fact that respiratory distress is usually the first presentation following ingestion and subsequent aspiration of hydrocarbon due to the resultant hypoxiawith minimal findings on chest radiograph (Levine, 2013).

A relatively high incidence of cases presented with respiratory distress following combined ChEIs and hydrocarbon exposure on admission was noted and agreed with Eddleston et al. (2004) who found that hydrocarbon aspiration may complicate ingestion of liquid concentrates of organophosphate pesticides with occurrence of respiratory distress before the development of pulmonary edema.

Corrosive cases showeda high incidence of respiratory distress followed bypneumonia as an indication of ICU admission. This can be explained bythe fact that respiratory distress is usually indicative ofassociated laryngeal edema and pneumonitis with impaired gas exchange due to direct inhalation or aspiration of vomitus containing the corrosive (McGuigan, 1999).

Respiratory failure was the commonest cause of ICU admission among carbon monoxide intoxication cases, whichcoincides with C-MAC (2008).CO-associated respiratory failure occurs due to several mechanisms including replacing oxyhemoglobin by carboxy-hemoglobin and binding of carbon monoxide to intracellular carriers of oxygen that cause tissue asphyxia, in addition to acute lung injury due to direct toxic effects on the alveolar membrane, aspiration pneumonia following loss of consciousness , and finally weakness of the respiratory muscles (Tomaszewski, 2006 and Weaver, 2009).

The mean duration of ICU stay of all cases in this study was 4.01days . This is in contrast to datastatedin a study performed in Spain by Burillo Putze et al., (2008) who found thatthe majority of acutely intoxicated cases are discharged from the emergency department after less than 12- 24hours. However, there was statistically significant difference between different toxic agents as regards duration of ICU staywhere carbon monoxide cases represented the highest mean duration of stay. This was similarly reported by Henry et al., (2006) wholinked the prolonged duration of ICU stay in carbon monoxide cases to the severity of morbidity due to anoxic brain injury, myocardial injury, and development of respiratory failure, seizures, and coma. On the other hand, hydrocarbon cases represented the lowest mean duration of stayashydrocarbon poisoning usually subsides after 24-48 hours and few cases require mechanical ventilation (Singh et al., 2009). 
In the current study, more than half of cases (54.4\%) showed respiratory acidosis. This coincides with Kollef and Isakow (2011) who reported that acute respiratory acidosis result from many disorders that acutely interfere with any component of the ventilatory mechanism such as the central or peripheral nervous system, neuromuscular junction, respiratory muscles, chest wall, pleura, upper airway, or lungs. Interference leads to hypoventilation with increased partial pressure of arterial carbon dioxide ( $\mathrm{PaCO} 2)$.

Mixed respiratory and metabolic acidosis also represented relatively high percentage (30.2\%). This can be explained according to Stewart, (2013)by the fact thatmixed acidosis is related to respiratory problems associated with severe prolonged hypoventilation causing hypercapnia (respiratory acidosis) in addition to severe prolonged hypoxia that leads to metabolic acidosis.

Respiratory alkalosis is particularly common among the critically ill, especially with severehypoxemia (as a major stimulus of alveolar ventilation); however it can be effectively corrected by mechanical ventilation (Madias and Adrogué, 2000).This may explain the low percentage of respiratory alkalosis in the present study which may be missed as mechanical ventilation was employed in management.

There was statistically significant difference between different toxic agents in the arterial blood gases pictures. The main presentation in $\mathrm{ChEI}_{\mathrm{S}}$ cases was respiratory acidosis, followed by combined respiratory and metabolic acidosis. Similar results were detected by Eddleston et al. (2006) and Byrd, (2013) who attributed the occurrence of acute respiratory acidosis with ChEIs to the abrupt failure of ventilation as a result of combination of paralysis of the diaphragm and intercostal muscles, depression of the brain respiratory center, bronchospasm, and excessive bronchial secretions.

As regard the hydrocarbon cases, the main presentation was respiratory acidosis. Singh et al., (2009) and Rodricks et al. (2003) related the increased association of respiratory acidosis with hydrocarbon poisoning to the occurrence of pneumonitis, and pulmonary edema in addition to central respiratory depression and finally respiratory failure following exposure.

Similarly, respiratory acidosis was also the commonest acid base disturbances in the combined ChEIs and hydrocarbon cases.

Analysis of the acid base results noted among the corrosive cases in this study revealed that mixed respiratory and metabolic acidosis were the commonest disorder.Respiratory acidosis related to aspiration of the corrosive substance was due to bronchoconstriction, chemical pneumonitis, inhalation bronchopnemnia, Mandelson syndrome and pulmonary edema with subsequent hypoventilation. While the associated metabolic acidosis is generated by elevated lactate from necrotic tissue or hemodynamic compromise due to hypovolemia following hemorrhage, vomiting and third-space sequestration (Turan et al., 2000 and Raghu et al., 2012).

Respiratory acidosis was also the commonest acid base disturbances among carbon monoxide cases. These results agreed with those reported by Tomaszewski (2006) and Byrd (2013), who related the occurrence of respiratory acidosis late in the process of $\mathrm{CO}$ poisoning to the development of severe pulmonary disease as pulmonary edema, pneumonia, weakness of the respiratory muscles and respiratory arrest.

The major indication of mechanical ventilation is respiratory failure, the end results of any severe lung disease (Kumar and Clark, 2005). In the present study, mechanical ventilation was needed in $43 \%$ of cases.However the leading indications for mechanical ventilation werecarbon monoxide poisoning, followed bycholinesterase inhibitors and combined ChEIs and hydrocarbons: all sharing the possibility of severe respiratorycompromise where mechanical ventilation is indicated. This is in contrast to themanagement in hydrocarbon poisoning which is principally conservative and mechanical ventilation is only required in few cases with inadequate oxygenation, severe respiratory distress or decreased level of consciousness (Singh et al., 2009).

In our study the fate of the majority of cases was complete cure $(75.2 \%)$, while mortality and morbidity occurred in $16.8 \%$ and $8.1 \%$ respectively. An association was also found between carbon monoxide and mortality.Carbon monoxide poisoning is considered to be one of the leading causes of death and injury worldwide (Smollin and Olson, 2010). Effects of severe poisoning may be life-threatening, including cardiac arrhythmias, myocardial ischemia, cardiac arrest, hypotension, respiratory arrest, non-cardiogenic pulmonary edema, seizures, and coma.

This can be explained according to Kirk and Pope (2006) who stated that although most critically ill poisoned patients have acute reversible conditions requiring supportive care measures, poisoning may produce both anticipated and unanticipated complications that can prolong ICU care and decrease survival such as pulmonary compromise, global cerebral anoxia and aspiration pneumonia.

\section{Conclusion and recommendations}

Poisoning due to household chemicals is a significant health problem increasing the burden on the health care system due to the resultant morbidity and mortality. This can be reduced by introduction of safer ingredients in household chemical products, better enforcement of childproof containers, educational measures aimed at improving poison awareness,and advertising telephone numbersof poison control centers. Labels of household productsmustalso provide concise, accurate first aid instructions in easy-tounderstand language. 
Attention should also be drawn towards the establishment of regional poison treatment centers to decrease delay time with properly trained physicians committed to clinical toxicology for proper diagnosis and treatment. It will be important to provide continuing medical education for the primary care physician for proper supportive management prior to the referral to poison control centers.

While the results of the present study showed a pilot insight about the patterns of the patients admitted ICU of the Poison Control Center, a more detailed multicenter study is recommended taking into consideration a prolonged duration which would include more number of patientswith follow up data and laboratory confirmation of exposure.

\section{References}

Abdel Raouf A, El Gohary M, Oreby M, et al., (2012): A proposed new scoring system for hydrocarbon poisoning cases in children in Gharbia Governorate. Mansoura J Forensic MedClinToxicol.20 (1).

Al-Shehri MA (2004): Pattern of childhood poisoning in Abha City - Southwestern Saudi Arabia. J Family Community Med. 11(2): 59-63.

Arici MA, Ozdemir D, Oray NC, et al., (2012): Evaluation of caustics and household detergents exposures in an emergency service. Hum Exp Toxicol. 31(6):533-8.

Balme KH, Roberts JC, Glasstone M et al., (2012): The changing trends of childhood poisoning at a tertiary children's hospital in South Africa. SAMJ.102 (3):142-6.

Bronstein AC, Spyker DA, Cantilena LR, et al. (2011): Annual report of the American Association of Poison Control Centers' National Poison Data System (NPDS): 29th annual report. ClinToxicol (Phila).50:911.

Burillo Putze G, Munne Mas P, DuenasLaita A, et al., (2008): Acute poisoning: an epidemiological and clinical profile and analysis of the digestive tract decontamination techniques used in emergency departments in Spain in 2006.Emergencias. 20: 15-26.

Byrd RP (2013): Respiratory Acidosis, sited in: http://emedicine.medscape.com/article/30157 4.

Cantrell FL, Nordt SP and Krauss JR (2013): Inconsistencies in emergency instructions on common household product labels. J Community Health. 38(5):823-8.

Chowell G, Díaz-Dueñas P, Bustos-Saldaña R et al., (2006): Epidemiological and clinical characteristics of scorpionism in Colima, Mexico (2000-2001). Toxicon. 47 (7): 753758.

C-MAC, (2008): Carbon monoxide awareness coalition of Pittsburgh and Allegheny County, $4^{\text {th }} \mathrm{ed}$, www.achd.net
Deorari A (2005): NNF teaching aids: newborn care. WHO-CC for training and research in newborn care, www.newbornwhocc.org.

Eddleston M (2008): The pathophysiology of organophosphorus pesticide self-poisoning is not so simple. Neth J Med. 66:146-8

Eddleston M, Karunaratne A, Weerakoon M, et al., (2006): Choice of poison for intentional selfpoisoning in rural Sri Lanka. Clinical Toxicology 44(3):283-286.

Eddleston M, Dawson A, Karalliedde L, et al., (2004): Early management after self-poisoning with an organophosphorus or carbamate pesticide a treatment protocol for junior doctors. Crit Care. 8(6):R391-397.

Ekpe EE and Ette V (2004): Mortality and morbidity of caustic ingestion in rural children: Experience in a new cardiothoracic surgery unit in Nigeria. ISRN Pediatric2012:1-4

El Masry M and Tawfik HM (2011): 2011 Annual report of the Poison control Center of Ain Shams University Hospital, Cairo, Egypt. Ain Shams $J$ of forensic medicine and clinical toxicology 20:10-17

Fishel F and Andre P (2002): Pesticide poisoning symptoms and first aid, missouri.edu/main/index.aspx.

Fook SM, Azevedo EF, Costa MM, et al., (2013): Poisoning with household cleaning products in a city in Northeast Brazil, Cad Saude Publica. 29(5):1041-5.

Ghoneim AH, Hussein RM, El-Ghamry Ret al., (2013): Patterns of admitted cases to Respiratory Intensive Care Unit at Zagazig University Hospitals, Egypt. Egypt. J. Chest Dis. Tuberc. 62(4):661-668

Habib RR, El-Masri A, and Heath RL (2006): Women's strategies for handling household detergents.Environ Res. 101(2):184-94.

Henry CR, Satran D, Lindgren B, et al., (2006): Myocardial injury and long-term mortality following moderate to severe carbon monoxide poisoning. JAMA. 2006; 295(4):398-402.

Hoffman RS (2006): Respiratory Principles, In: Goldfrank's Toxicologic Emergencies, Flomenbaum NE et al. (eds), $8^{\text {th }}$ ed. , McGraw-Hill Companies, New York, USA. Ch. 22. pp. 361-353.

Holland MG (2007): Pulmonary Toxicology, In: Shannon: Haddad and Winchester's Clinical Management of Poisoning and Drug Overdose, $4^{\text {th }}$ ed., Saunders Company, Philadelphia USA, Chapter 9.

Johnson CM and Brigger MT (2012): The public health impact of pediatric caustic ingestion injuries.Arch Otolaryngol Head Neck Surg. 2012 Dec; 138(12):1111-5. 
Kao LW and Nañagas KA (2004): Carbon monoxide poisoning. Emerg Med Clin N Am. 22:9851018.

Kirk MA and Pope JS, (2006): Use of the intensive care unit, In: Goldfrank's Toxicologic Emergencies, Flomenbaum NE et al.(eds), $8^{\text {th }}$ ed. , McGraw-Hill Companies, New York USA,Ch.11.p.174-79.

Klepac T, Buljeta I, Macan J, et al., (2000): Household chemicals-common cause of unintentional poisoning .ArhHigRadaToksikol51:401-407

Kollef M and Isakow W (2011): Respiratory acid-base disorders, In: The Washington Manual of Critical Care, $2^{\text {nd }}$ ed., Lippincott Williams and Wilkins, Philadelphia, USA, Ch. 26, p.223226.

Kumar P and Clark M (2005): Essential of Kumar and Clark clinical medicine $6^{\text {th }}$ ed, Edinburgh: Saunders Elsevier ch.15 pp849-856

Levine MD (2013): Hydrocarbon toxicity: http://emedicine.medscape.com/article/82114 3-overview

Lupa M, Magne J, Guarisco JL et al., (2009): Update on the diagnosis and treatment of caustic ingestion. The Ochsner J. 9:54-59.

Madias NE and Adrogué HJ (2000): Respiratory alkalosis and acidosis. In: The Kidney: Physiology andPathophysiology. Seldin DW and Giebisch $\mathrm{G}$ (eds), $3^{\text {rd }}$ ed, Lippincott Williams and Wilkins, Philadelphia USA, pp. 2131-2166.

Manzar N, Saad SMI, Mansar B, et al., (2010): Thestudy of etiological and demographic characteristics of acute household accidental poisoning in children - a consecutive case series study from Pakistan .BMC Pediatrics. 10:28.

Marrie TJ and Shariatzadeh MR (2007): Communityacquired pneumonia requiring admission to an intensive care unit: a descriptive study. Medicine (Baltimore) 86(2):103-11.

McGuigan MA (1999): Common culprits in childhood poisoning: epidemiology, treatment, and parental advice for prevention. Ped Drugs1(4):313-324.

Meyer S, Eddleston M, Bailey B, et al., (2007): Unintentional household poisoning in children. Klin Padiatr. 219(5):254-70.

Palmer RB and Phillips SD, (2007): Hydrocarbons, In Shannon: Haddad and Winchester's Clinical Management of Poisoning and Drug Overdose, 4th ed., Saunders Company, Philadelphia USA, Chapter 93.

Presgrave RF, Camacho LA, and Villas Boas MH (2008): A profile of unintentional poisoning caused by household cleaning products, disinfectants and pesticides. Cad Saude Publica. 24(12):2901-8.

Raghu R, NaIk R, and VadIvelan M (2012): Corrosive poisoning. Indian Journal of Clinical Practice 23 (3).

Rodricks A, Satyanarayana M, D'Souza GA, et al., (2003): Turpentine-induced chemical pneumonitis with broncho-pleural fistula. J Assoc Physicians India, 51:729-30

Sadaka Y, Broides A, Tzion RL, et al., (2011): Organophosphate acetylcholine esterase inhibitor poisoning from a home-made shampoo. J Emerg Trauma Shock, 433-434.

Sideras J (2008): Evaluating and treating carbon monoxide poisoning, http//:www.ems1.com

Singh R, Vinayagam S, and Vajifdar H (2012): Methemoglobinemia as a result of accidental lacquer thinner poisoning. Indian J Crit Care Med. 16(1): 44-47.

Singh UK, Prasad R, and Gaurav A (2009): Hydrocarbon and related compounds poisoning, Indian Journal of Practical Pediatrics vol.11 (1), p.15-22.

Smith DC (1999): Acute inhalation injury. Clin Pulm Med. 6:224-235.

Smollin C and Olson K (2010): Carbon monoxide poisoning (acute). Clin Evid (Online). 2010:2103.

Stewart JS (2013): Tissue hypoxia and metabolic acidosis significant factors. Postgrad Med J. 45 (526): 518-521.

Sulastri S, NurAfni A, and Zyoud SH (2012): Cases of accidental hydrocarbon ingestion referred to the Malaysian National Poison Center. 10th Scientific Congress of the Asia Pacific Association of medical toxicology. In: annual meeting abstracts. J Med Toxicol. 8(2): 192237.

Tomaszewski C (2006): Carbon monoxide. In: Goldfrank's Toxicologic Emergencies, Flomenbaum NE et al.(eds), $8^{\text {th }}$ ed., McGrawHill Companies, New York USA .Ch 120

Tracqui A, Flesch F, Sauder P, et al., (2001): Repeated measurements of aldicarb in blood and urine in a case of nonfatal poisoning. Hum ExpToxicol. 20:657-660.

Turan C, Ozkan U, and Ozokutamn BH (2000): Corrosive injuries of the esophagus in newborns. Pediatr Surg Int. 16(7): 483-4

Weaver LK (2009): Clinical practice. Carbon monoxide poisoning, $\mathrm{N}$ Engl $\mathrm{J}$ Med. 360(12):1217-25. 
الملخص العربي

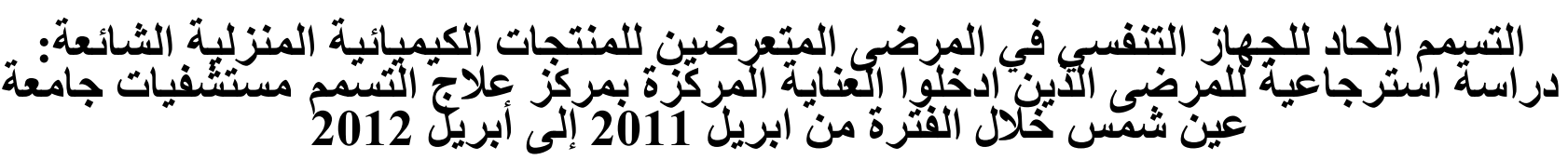

منال السيد عبد السلام وهدى محمد صلاح الدين و نهى محمد أحمد عوض1 1

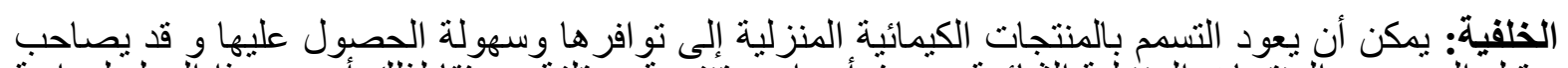

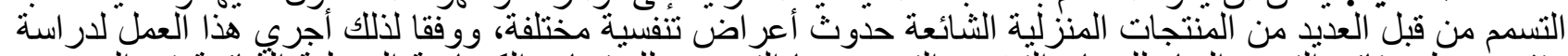

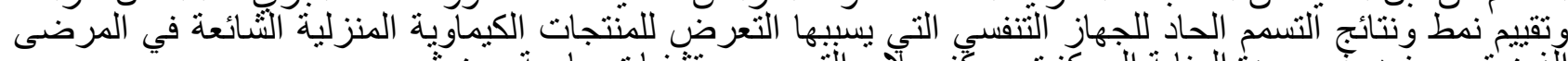

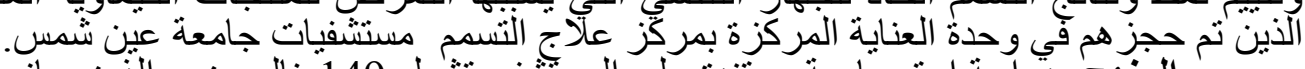

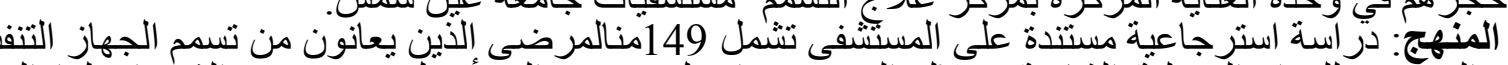

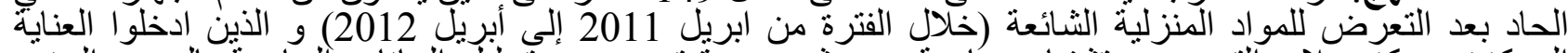

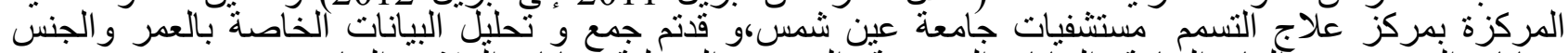

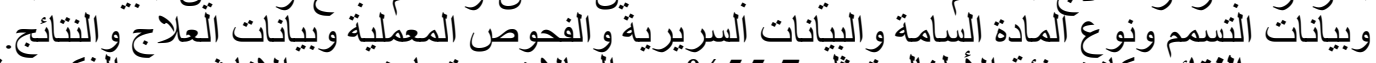

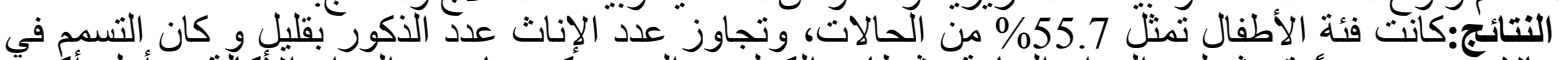

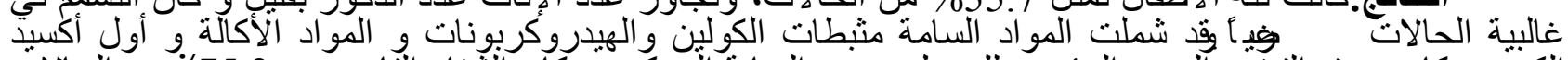

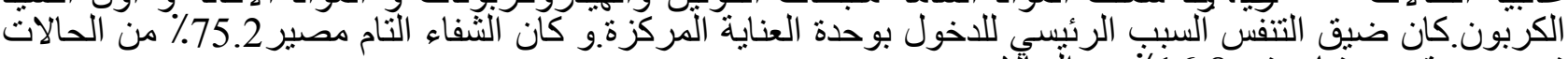

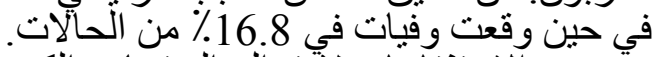

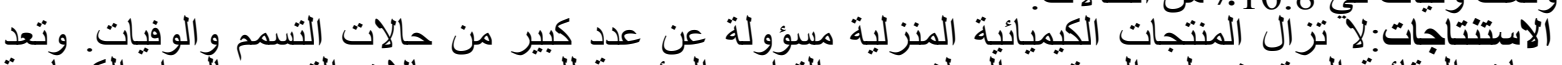

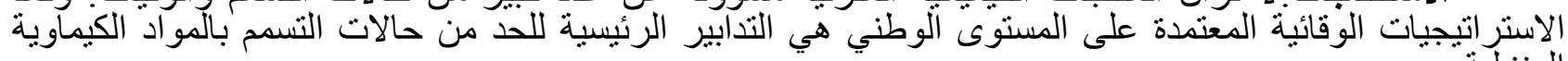

المنزلية.

1 قسم الطب الثرعي و السموم الإكلينيكية كلية الطب جامعة عين شمس 